\title{
A method of estimating the depths of shallow water based on the measurements of upwelling irradiance
}

\author{
Krzysztof Pyrchla $^{1}$ (D) . Aleksandra Dworaczek ${ }^{1} \cdot$ Aleksandra Wierzbicka $^{1}$
}

Received: 19 May 2015 / Revised: 8 March 2018 / Accepted: 11 March 2018 / Published online: 20 March 2018 (C) The Author(s) 2018

\begin{abstract}
Aerial photography of shallow water areas can provide useful quantitative information on water depth. The accuracy of bathymetric data read directly from aerial photographs is dependent on the environmental conditions and the use of an appropriate model. This paper proposes a method for determining water depth using measurements of the light intensity emitted from the water in aerial photographs captured by photogrammetric cameras. Presented results of research are addressed to practical usage in tasks related to ecology, recreation, and coastal management. The developed model is trained using field measurements of bathymetry. Unlike previously proposed methods, this method does not require the use of hyperspectral cameras. In this study, field experiments are combined with mathematical descriptions of coastal areas, and an analysis of the uncertainty of the results is presented. Using the proposed solution to calculate depths should enable rapid execution of bathymetry over a large area with a relatively small outlay of funds. This method was tested in practice at the Baltic coastal resort of Rowy, in which the bathymetry was set at a depth of $1.2 \mathrm{~m}$.
\end{abstract}

Keywords Bathymetry $\cdot$ Aero photographic imagery $\cdot$ Foreshore $\cdot$ Light extinction coefficient $\cdot$ Remote sensing

\section{Introduction}

Coastal basins are very sensitive to depth changes. Safety of recreation and leisure of people depends on the speed of detection of this changes. Presented solution is innovative because it gives the possibility to rapid depth estimation on large areas with neglectable costs. The critical aspect is a synergetic connection of remote sensing with the geographic information system (GIS). This connection provides the automatic creation of the bathymetric map from data collected by photogrammetric cameras. These maps are interesting for people responsible for recreation and building of coastal infrastructure. The first group is interested in actual bathymetric data second is also concerned with trends of depth changes. The presented method is suitable for both groups requirements. Because of the high speed of and low cost, the measurements can be frequent. The result is the up-to-dateness of bathymetric

Krzysztof Pyrchla

krzpyrch@student.pg.gda.pl

1 Gdansk University of Technology, Gabriela Narutowicza 11/12, 80-233 Gdańsk, Poland data and accurate prediction of changes in depth of coastal basins.

Studies examining the optical properties of oceans and seas have been underway for almost two centuries (Maffione 2001). During this time, significant efforts have been made by scientists and engineers to use available technology properly. Past research efforts have led to the development of specific techniques for determining coefficients that describe the environmental conditions based on aerial photographs (Polcyn et al. 1970; Wezernak and Lyzenga 1975; Lyzenga 1978). Such studies primarily concern water measurements performed in open waters and involve the determination of the light attenuation in marine waters (Hakvoort et al. 2000; Dera and Sagan 1990). The designation of these factors is essential for studying optical properties of deep-water reservoirs such as the Baltic Sea (Levin et al. 2013). However, these studies focus on analyzing optical data at an angle to determine the water depth (Polcyn and Lyzenga 1973; Lyzenga and Thomson 1976; Lyzenga 1978).

In these areas, the values of the light attenuation coefficients in the water are determined by many factors that are difficult to specify precisely. Both scattering and absorption processes lead to a decrease in light intensity; 
the effect of their actions is known as the attenuation of light. The value of the light attenuation coefficient " $c$ " is the sum of the absorption coefficient " $a$ " and the scattering "b" (Ficek 2013; Mobley et al. 2009). To describe these processes, an equation of radiative energy transfer is used. This equation describes the dependence of the decrease in the initial amount of radiation $(L)$ to the thickness of the water layer $(d h)$ relative to the product of the initial value of the radiation $(L)$ and the light attenuation coefficient in the water (c). An additional factor considered in the description of this process is the amount by which the light beam is increased by randomly distributed light rays originating from other directions ( $L_{*}$, function load). This study also includes the source function $\left(L_{n}\right)$, which is additional radiation originating from internal light sources such as microorganisms and Raman scattering. Assuming that the radiation does not change over time, this equation can be written as

$\frac{d L}{d h}=-c L+L_{*}+L_{n}$.

This equation has no general solution; therefore, a solution can be found only for a particular case. The method presented here is characterized by a series of assumptions that are based on a theoretical analysis of the phenomena occurring in the water. The cases presented in this article are related to a water depth of $1.5 \mathrm{~m}$, which is a notably thin layer compared with the depth of $90 \mathrm{~m}$ used in the analysis of light propagation. This paper describes research investigating the shallow and very clear waters of a coastal area. Given this, processes of additional radiation originating from internal light sources such as microorganisms and Raman scattering have no impact we can skip the source function $\left(L_{n}\right)$.

The hypothesis is that it is possible to measure depths in areas of shallow water bodies by measuring the intensity of the upwelling spectral radiance from the water. The coefficients for the described method are determined from a summary of data collected by cameras with direct measurements of the depth. The proposed method assumes that at such small depths (from 0 to $1.5 \mathrm{~m}$ ), light scattering and backscattering (except the scattering in the original direction) can be ignored. Related research will be presented for discussion (Gilabert et al. 1995).

\section{Materials and methods}

The assumption of a relatively small thickness for the water layer suggests that given such a small travel distance in water, the scattered light rays will have minimal influence on the other light rays traveling in the original direction (Gilabert et al. 1995). The radiation is scattered primarily in its original "forward" direction. For such assumptions, we can say that scattering will only increase the effect of attenuation caused by absorption.

The present method assumes that measurements are performed in local climatic conditions during early spring or late autumn. These periods are characterized by water that is not significantly polluted concerning algae and microorganisms. If we apply Eq. 1 as a simplified mathematical description of the passage of rays through a layer of water, the factors $L_{*}$ and $L_{n}$ will be approximately equal to zero. Therefore, Eq. 1 reduces to the form of Eq. 2.

$\frac{d L}{d h}=-c L$.

It was assumed that the beam of light is parallel. In such a case, Eq. 2 is following the Bouguer law, which takes the form

$\frac{I_{b}}{I_{a}}=e^{-\alpha h}$.

In this equation, $I_{a}$, the intensity of the light penetrating the water, is referenced to $I_{b}$, the intensity of light after passing through a layer of water with thickness $h$ and a light attenuation coefficient $\alpha$. However, the previously mentioned conditions do not determine all of the parameters required for the proper use of Eq. 3. They do not adequately describe the features of light incident on the water's surface because they do not consider the type of beam or the angle of incidence. This equation assumes that the incident beam is monochromatic, which does not occur in practice because the sea surface is illuminated by solar radiation (approximately white light). According to research conducted by Clarke and James, the coefficient $\alpha$ is dependent on the frequency of the radiation beam. In that study, the dependence is manifested primarily at both ends of the visible light range. In the present study, the relationship was taken as a constant in the middle of the visible light range.

Another phenomenon that occurs with the passage of light through water is the reflection. A reflection occurs when the light beam reaches the bottom of the water body; reflection also occurs at the surface. Electromagnetic wave reflection is described by the reflectance coefficient $(R)$, which is defined as the ratio of the reflected wave intensity from the surface $\left(I^{\prime}\right)$ to the intensity of the wave falling on a given surface $(I)(4)$.

$R=\frac{I^{\prime}}{I}$.

If we accept again that the surface is illuminated by parallel rays with incidence perpendicular to the surface, we can assume that the reflectance of the opaque material is a characteristic property. However, the situation is different when the reflection occurs at the border of 
two environments with different transparent indices of refraction: $n_{1}$, the refractive index of the first environment, and $n_{2}$, the refractive index of the second environment. In this case, the reflection coefficient depends only on the relative refractive indices of the environment (5).

$R=\left(\frac{n_{1}-n_{2}}{n_{1}+n_{2}}\right)^{2}$.

When the above assumptions are adopted, we can create a mathematical model describing the propagation of light in the water. Let us consider parallel light rays with incidence perpendicular to a smooth surface. In accordance with the assumptions regarding the value of the light intensities of reflections entering the water layer (4 and 5) and those reflecting from the surface, we can describe this phenomena with Eqs. 6 and 7, where $n_{1}$ is the water's refractive index, and $n_{2}$ is the air's refractive index:

$I^{\prime}=I\left(\frac{n_{1}-n_{2}}{n_{1}+n_{2}}\right)^{2}$,

$I_{a}=I\left[1-\left(\frac{n_{1}-n_{2}}{n_{1}+n_{2}}\right)^{2}\right]$.

The light beam with initial intensity $I_{a}$ traveling across the water layer is attenuated (Fig. 1). This attenuation is described according to the first assumption (3). In effect, we obtain the formula of illumination of the bottom of the water body (8).

$I_{b}=I_{a} e^{-\alpha h} \Rightarrow I_{b}=I e^{-\alpha h}\left[1-\left(\frac{n_{1}-n_{2}}{n_{1}+n_{2}}\right)^{2}\right]$

Part of the light beam reaching the bottom part of the water is absorbed, and part is returned to the surface. Using the assumption concerning the reflectance (4), we obtain the relationship between the intensity of light reaching the bottom and the intensity reflected from the bottom $\left(I_{c}\right)$ (Fig. 1b) in the form of Eq. 9.

$I_{c}=I R_{d} e^{-\alpha h}\left[1-\left(\frac{n_{1}-n_{2}}{n_{1}+n_{2}}\right)^{2}\right]$.

A beam of light reflected from the bottom $\left(R_{d}\right.$, the bottom reflectance coefficient) is attenuated when it is moving through the water layer again according to Eq. 3. As a result of this phenomenon, light with intensity $I_{d}$ returns to the surface, as described by Eq. 10 .

$I_{d}=I R_{d} e^{-2 \alpha h}\left[1-\left(\frac{n_{1}-n_{2}}{n_{1}+n_{2}}\right)^{2}\right]$.

However, considering the re-reflection from the boundaries of the different environments, the intensity of light emitted from the water $\left(I_{e}\right)$ is described by Eq. 11. The distribution of these intensities is presented in Fig. $1 \mathrm{~b}$.

$I_{e}=I R_{d} e^{-2 \alpha h}\left[1-\left(\frac{n_{1}-n_{2}}{n_{1}+n_{2}}\right)^{2}\right]^{2}$

Note that the intensity of light that would be registered by a detector placed above the surface of the water (and facing downward) is composed of intensity $I^{\prime}$ and $I_{e}$. We can further assume that the intensities of individual light beams are combined additively. We define $I_{z}$ as the sum of the intensity of the light beam directed from the water surface upwards, and we generate formula (12) and the resulting formula (13).

$I_{z}=I^{\prime}+I_{e}$.
Fig. 1 Intensity distribution of the light beam when passing through a layer of water: a light transmission through the water layer; $\mathbf{b}$ relationship between the intensity of light reflected from the bottom and the light intensity directed from the water (a)

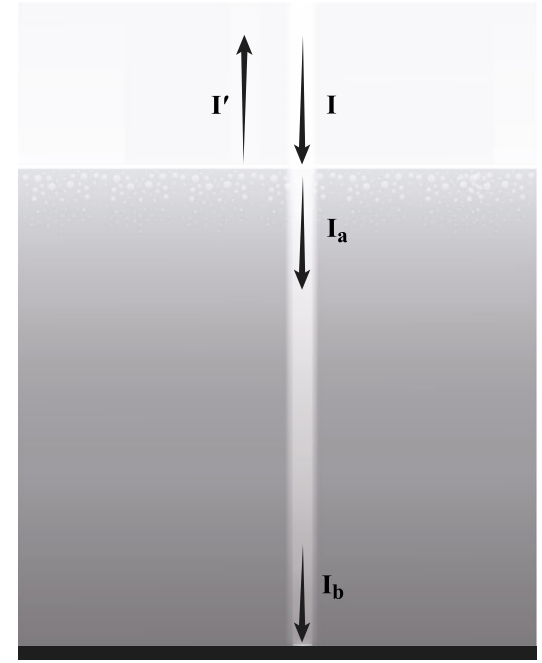

(b)

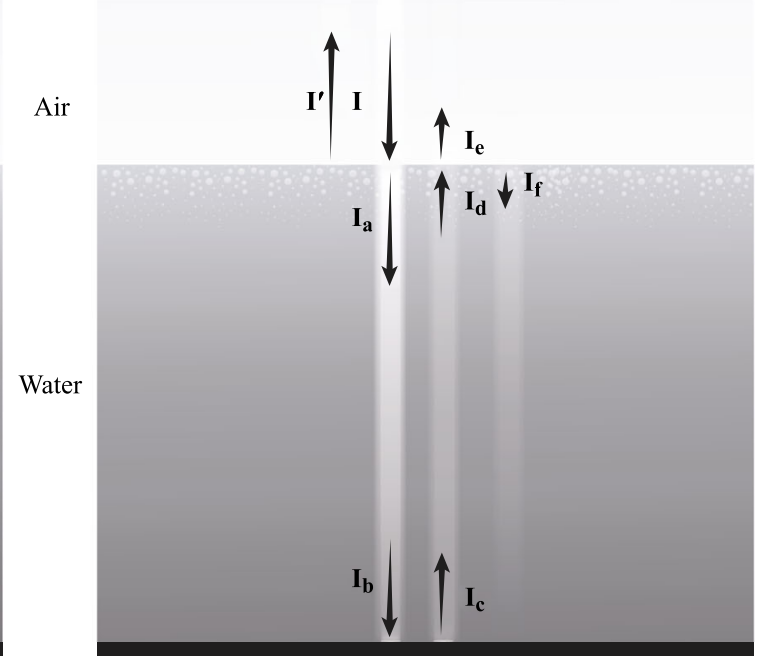


$h=\frac{\ln \left[\frac{I_{z}-I\left(\frac{n_{1}-n_{2}}{n_{1}+n_{2}}\right)^{2}}{I R_{d}\left(1-\left(\frac{n_{1}-n_{2}}{n_{1}+n_{2}}\right)^{2}\right)^{2}}\right]}{-2 \alpha}$.

The above equation can be simplified to a function of one variable by introducing the dimensionless parameter $N$. Additionally, we can demonstrate that the solution to this equation does not depend on the unit in which the variables $I$ and $I_{z}$ are expressed. Parameter $N$ is defined by Eq. 14 .

$N=\frac{I_{z}}{I}$.

We can then write our equation as

$h=\frac{\ln \left[\frac{N-\left(\frac{n_{1}-n_{2}}{n_{1}+n_{2}}\right)^{2}}{R_{d}\left(1-\left(\frac{n_{1}-n_{2}}{n_{1}+n_{2}}\right)^{2}\right)^{2}}\right]}{-2 \alpha}$.

Formula (15) can be expressed as

$$
\begin{aligned}
h & =\frac{\ln \left[N-\left(\frac{n_{1}-n_{2}}{n_{1}+n_{2}}\right)^{2}\right]}{-2 \alpha}-\frac{\ln \left[R_{d}\left(1-\left(\frac{n_{1}-n_{2}}{n_{1}+n_{2}}\right)^{2}\right)^{2}\right]}{-2 \alpha} \\
& =\frac{1}{-2 \alpha} \ln \left[N-\left(\frac{n_{1}-n_{2}}{n_{1}+n_{2}}\right)^{2}\right]-\frac{\ln \left[R_{d}\left(1-\left(\frac{n_{1}-n_{2}}{n_{1}+n_{2}}\right)^{2}\right)^{2}\right]}{-2 \alpha},
\end{aligned}
$$

where $h$ is a function of $N$.

The value of the introduced $\mathrm{N}$ parameter for the points on the water surface was calculated according to the formula for albedo (4). As indicated in each photo, the reference surface was the beach $\left(R_{p}\right)$, in which the sand albedo was assumed to be 0.3 (Chadyšiene and Girgždys 2008). $I_{p l}$ denotes the average value of color brightness in the entire area of visible dry beach in the image. It should be noted, that color brightness is determined as an average brightness of all used band. With these assumptions, the parameter $N$ for the presented orthophotograph is shown in Eq. 17.

$N=\frac{I_{z} R_{d}}{I_{p l}}$.

The parameter $\mathrm{N}$ enables the elimination of inconsistency in the units.

The usage of the proposed model to estimate depth requires knowledge about two parameters: attenuation of radiation intensity in the water and the bottom reflection. Thus the inconstancy of these parameters on the vast areas of seacoast is essential to provide actual information. We could achieve required parameters using a small group of points in which depth is known from direct measurements. This measurement points will be called reference points.
The dimensionless value of the parameter $N$ (defined by Eq. 14) was read from an orthophotograph of the experimental area for each reference point. The intensities of the beams reflected from various surfaces were read from the images as average values of the color brightness in these areas. $I_{z}$ denotes the average value of color brightness within a circular area of radius $0.5 \mathrm{~m}$ centered at the measurement point. The radius of this area is determining the resolution of the final map. From because of that it should be chosen as a compromise between better accuracy of the color brightness value and size of the area within depth will be estimated as a constant. We can see that final quality of produced map depends on the resolution of used orthophotomap. To provide both good accuracies of estimated depth and density of bathymetric points, the pixel size of orthophotomap must be reduced by order of magnitude than the size of the pixel of the bathymetric map. In presented case the pixel size of used images corresponded to $0.01 \mathrm{~m}^{2}$. The next step in preparing the data is to produce a dispersion graph of the parameter $N$ in relation to the depth (Fig. 3). The refractive index of water used was $n_{1}=$ 1.33, and the refractive index of air was 1.0. Based on the data from the measurements in Rowy, we used the program Mathematica to fit a function with an offset argument of the form

$h=a \ln [x-(\ldots)]-b$.

which has the same form as Eq. 16. This function gives us a system of two equations with two unknowns,

$\left\{\begin{array}{l}\frac{1}{-2 \alpha}=a \\ \frac{\ln \left(R_{d} \cdot 0.960365304\right)}{-2 \alpha}=b\end{array}\right.$,

from which the following coefficients can be determined: attenuation of radiation intensity in the water $\alpha$ and the bottom reflection $R_{d}$.

This analysis describes a method for formally estimating the depth of water in coastal areas. The presented mathematical descriptions of the phenomena are reasonable, and the assumptions used are described at the beginning of the theoretical considerations. The presented model is the starting point for described research, which includes verification under actual conditions.

For the experiments, the direct measurements of depth were performed using a Leica Viva CS15 Real Time Kinematic (RTK) mobile receiver with a built-in Global System for Mobile communications (GSM) to connect with the network of reference stations. During the measurements, the ASG-EUPOS reference station network was used. The accuracy of the height measurements used for the model was $20 \mathrm{~mm}$. The GS15 model was mounted on a pole receiver and communicated wirelessly to the controller 
via Bluetooth, and the data were recorded in the internal memory of the receiver. The logged data can be postprocessed directly in the controller or using a computer after recording the data; the team employed the second option. When the unit was connected to the reference network, it was necessary to register the receiver positions with the altitude of the individual measurement points. The parameters were automatically converted and saved, and the height measurement was referenced to the local quasigeoid.

All used aero photographic were made using the UltraCam Eagle- digital photogrammetric camera systems, equipped with 260 megapixels frame size (the largest image resolution - $20010 \times 13080$ pixels). The photogrammetric design concept of the UltraCam Sensor Family is based on four camera heads for the sizeable panchromatic frame and four additional camera heads for multispectral sensing (red, green, blue and near-infrared). During the data processing only RGB bands were used.

The geospatial nature of collected data describing the seashore indicates that the GIS environment was selected for their analysis. The advantages of this environment for the analyses of other issues in the coastal area were noticed by other teams researching the seashore (Pais-Barbosa et al. 2012). A created GIS database was used to store data and incorporate them into interdisciplinary analyses. The proposed solution will facilitate the comparative study of physicochemical parameters in coastal geomorphology (Tibbetts and van Proosdij 2013; Kumar et al. 2014; Pyrchla et al. 2016; Kasyk et al. 2016; Janowski et al. 2015).

\section{Results}

The assumptions used to perform the experiments considered the topography of the nearest area. First, the measurements should be performed in a coastal area where the topography of the coast provides easy access to water. Second, the preliminary analysis should be conducted at locations in which the bottom is composed of sand. Third, it is recommended that the material on the shore and in the water be the same. This assumption is fundamental from an optical perspective and will facilitate the analysis of images from which the depth will be estimated.

Measurements were taken in April, through two years (2013-2014). After a preliminary analysis, the seashore in Rowy was selected. Photographs taken by MGGP Aero were used to perform the study on locations on the Polish coast. Direct depth measurements were performed precisely at the day when the aero photographic were taken. A disadvantage of this region is that a rapid change in depth occurs close to shore on isobaths above $0.8 \mathrm{~m}$. The locations of the measurements were indicated on the map Fig. 2 by using Arc GIS program 10.0.
Figure 2 presents an example of an aerial photograph, i.e., an orthophotograph, used to read the necessary data for depth estimation.

The example of the direct measurements of depth results are presented in Table 1; this data represents only part of the data registered by an RTK mobile receiver. The data presented are the geodetic positions of measurements and the registered depth.

Group of points presented in Table 1 was used as reference points. According to the described method the essential graph was made, and function was fitted to it. The resulting fit obtained was

$y=-1.11337 \ln [x-0.0200177]-0.75432$.

According to formula (19), in the present area, the values of essential parameters were $\alpha=0.449$ and $R_{d}=0.529$.

The values of the coefficients were used to estimate the depth at the measurement points identified in Table 2 with attachments from s1 to s5. This procedure was designed to check the effectiveness of the method in the field. The results are presented in Table 2, which compares the estimated depth to the values of the measured depth.

Determination of the uncertainty in the presented method was performed by examining the results. The primary concern was to determine the standard deviation of the regression coefficients. As part of the solution, we produced a linearisation graph of the measured depth " $h$ " and a defined factor " $N$ " (Fig. 4). After introducing the Fresnel reflection coefficient,

$F=\left(\frac{n_{p}-n_{w}}{n_{p}+n_{w}}\right)^{2}$,

to Eq. 16, it takes on the form of

$h=\frac{\ln [N-F]}{-2 \alpha}-\frac{\ln \left[R_{d}(1-F)^{2}\right]}{-2 \alpha}$.

Introducing a variable,

$x=\ln [N-F]$,

to Eq. 22, gives the linear relationship

$h=-\frac{1}{2 \alpha} x+\frac{\ln \left[R_{d}(1-F)^{2}\right]}{2 \alpha}$.

These considerations enable conversion of the logarithmic regression curve presented in Fig. 3 to a linear model described by Eq. 24, as shown in Fig. 4.

After the linearisation regression was conducted, the results were investigated using the Statistica program. The first step in this study was to test the hypothesis that the distribution of the variables is close to normal. To verify 


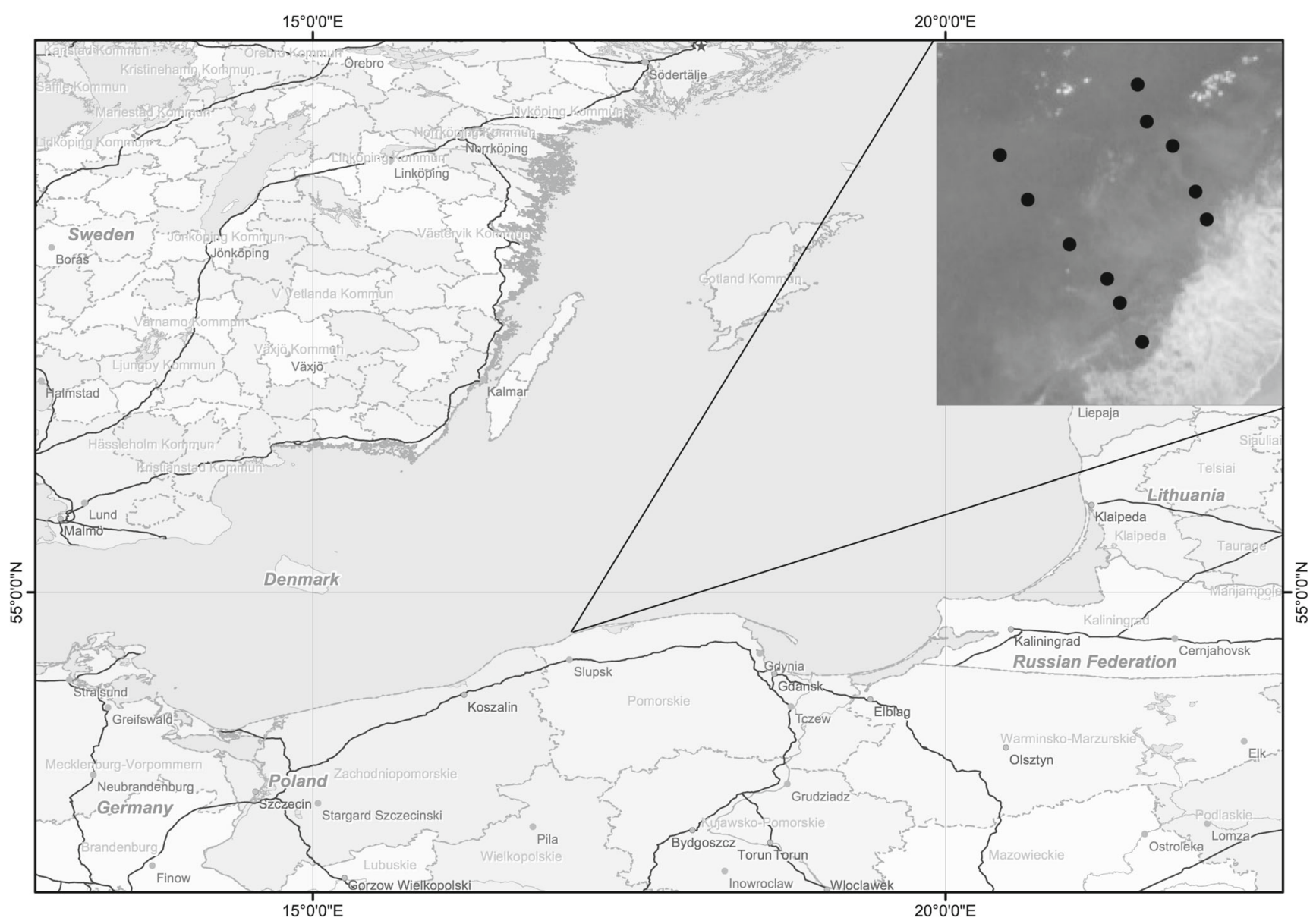

Fig. 2 Example of an orthophotograph at a scale of 1:125 with the selected measurement points indicated

this, the Shapiro-Wilk test was applied. The results $(W=$ 0.88071 and $p=0.07290$ ) confirm the accepted hypothesis of a normal distribution.

Table 1 Parameters set on the measurement points

\begin{tabular}{lllll}
\hline Point & $\mathrm{N}$ & $\begin{array}{l}\text { Measured } \\
\text { depth }\end{array}$ & B degree & L degree \\
\hline 1 & 0.3826 & 0.31 & 54.66589631 & 17.04348242 \\
2 & 0.3667 & 0.40 & 54.66590428 & 17.04347753 \\
3 & 0.2772 & 0.71 & 54.66597031 & 17.04344928 \\
4 & 0.2552 & 0.75 & 54.66598817 & 17.04343089 \\
5 & 0.2479 & 0.80 & 54.66599911 & 17.04342047 \\
6 & 0.2452 & 0.80 & 54.66601475 & 17.04339031 \\
7 & 0.3910 & 0.15 & 54.66595206 & 17.04362803 \\
8 & 0.4001 & 0.41 & 54.66596211 & 17.04361264 \\
9 & 0.3640 & 0.56 & 54.66597686 & 17.04359089 \\
10 & 0.2493 & 0.79 & 54.66603997 & 17.04349014 \\
11 & 0.2831 & 0.72 & 54.66602714 & 17.04349908 \\
12 & 0.2915 & 0.82 & 54.66619881 & 17.04379239 \\
13 & 0.2505 & 0.98 & 54.66622325 & 17.04375931 \\
14 & 0.2708 & 0.88 & 54.66631203 & 17.04391031 \\
15 & 0.2698 & 1.01 & 54.66632344 & 17.04389647 \\
\hline
\end{tabular}

The next step was to verify the correlation between the measured depth " $h$ " and the variable $x$ (23). We tested the null hypothesis that there is no correlation between the studied variables. An alternative hypothesis assumes that there is a correlation between the studied variables. Verification of these hypotheses was done using Student's t-test. The results, $r_{x y}=-0,915977, r^{2}=0.839014$, and $t=-7.57158$ with the confidence level $p=0.000011$, enable rejection of the null hypothesis and acceptance of the alternative hypothesis.

The test results hold that standard deviation of the linear regression coefficients determined by $S_{a}, S_{b}$ is needed.

$$
\begin{aligned}
& S_{a}=\sqrt{\frac{n}{n-2} \cdot \frac{\sum_{i=1}^{n} y_{i}^{2}-a \sum_{i=1}^{n} x_{i} y_{i}-b \sum_{i=1}^{n} y_{i}}{n \sum_{i=1}^{n} x_{i}^{2}-\left(\sum_{i=1}^{n} x_{i}\right)^{2}}} \\
& S_{b}=S_{a} \sqrt{\sum_{i=1}^{n} x_{i}^{2}}
\end{aligned}
$$

The following results were obtained: $S_{a}=0.0745$ and $S_{b}=0.0978$. Considering the linear regression in Eq. 24 
Table 2 Summary of the depth values determined by the proposed method for the test measurement series and the values of the measured depth

\begin{tabular}{llllll}
\hline Point & B degree & L degree & Estimated depth $[\mathrm{m}]$ & Measured depth [m] & Depth difference [m] \\
\hline s1 & 54.66650408 & 17.04422728 & 0.66 & 0.91 & 0.25 \\
s2 & 54.66651197 & 17.04421756 & 0.80 & 0.99 & 0.19 \\
s3 & 54.66652361 & 17.04420506 & 0.77 & 1.04 & 0.27 \\
s4 & 54.666589 & 17.04433128 & 1.05 & 0.97 & 0.08 \\
s5 & 54.66660094 & 17.04431039 & 0.99 & 1.07 & 0.08 \\
\hline
\end{tabular}

and the calculated standard deviations of the parameters, it is possible to set two extreme regression curves where $k$ is the number of standard deviations:

$y_{\max }=\left(a-k \sigma_{a}\right)+b+k \sigma_{b}$,

$y_{\text {min }}=\left(a+k \sigma_{a}\right)+b-k \sigma_{b}$.

The distance between the extreme regression curves is interpreted as twice the value of the depth uncertainty " $\sigma_{h}$ ":

$2 \sigma_{h}=y_{\max }-y_{\min }$.

Substituting Eqs. (27) and (28) in Eq. 29 gives

$\sigma_{h}=\left(\sigma_{b}-\sigma_{a} x\right) k$.

It should be noted that this formula is correct only for the analysed case. A different correlation curve would force a change in the number of characters in Eqs. 27 and 28.

Equation 30 gives the uncertainty in the respective depths using the presented method adopted in the check points. Table 3 shows the depth of the actual measurements, the estimated depth, and the uncertainty estimation $(\Delta h)$.

To recapitulate, the research results emphasize the practical dimensions of the obtained results and indicate the need for further study of the presented issues. Research can also be conducted by applying bathymetry for data analysis of computational intelligence (Eubczonek and Stateczny 2003; Stateczny and Wlodarczyk-Sielicka 2014; Stateczny 2000). This study's method assumed that the estimation of depth is based on experimentally determined coefficients. The broad diversity of materials covering the bottom demonstrates the need for further study. Estimation of depth using such a small number of measurements is not accurate. Analysis of the results obtained here led to the development of a function describing the relationship between depth and the parameter $N$. Studies examining this function should be continued. The possibility of determining the parameter $N$ using calibrated measurements could enable depth estimations in other areas of water. An example of the bathymetry of a coastal area determined using the proposed method is shown in Fig. 5. It is clear that the proposed method enables the determination of local depressions, which are highly dangerous for swimmers.

The initial hypothesis was that it is possible to estimate water depth in shallow areas using the intensity of light emitted from the water. Our research confirms this initial hypothesis. The results obtained during the testing of this method confirm the possibility of its practical application.
Fig. 3 Correlation graph of the function described by equation 15 showing the relationship between the parameter $\mathrm{N}$ and the calibration measurements of depth in the Rowy area.

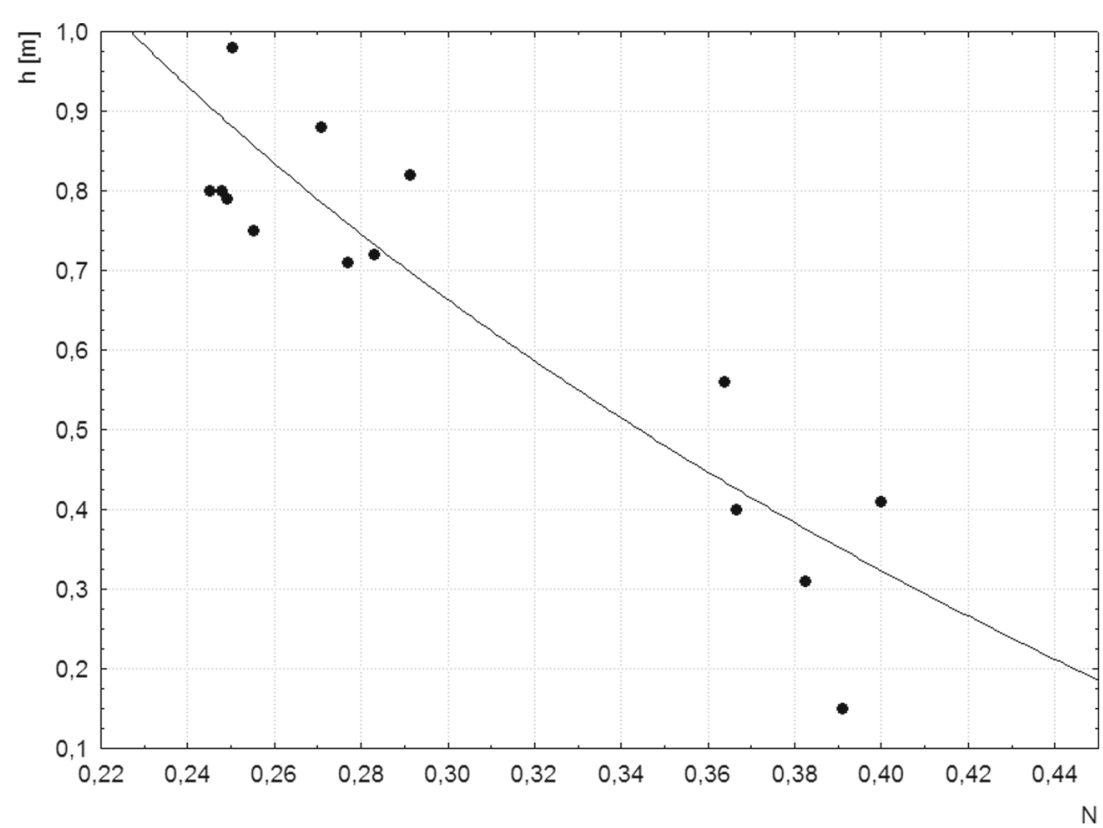


Fig. 4 Correlation graph of the function described by Eq. 24, giving the dependence between $x$ and the calibration measurements of depth in the Rowy area

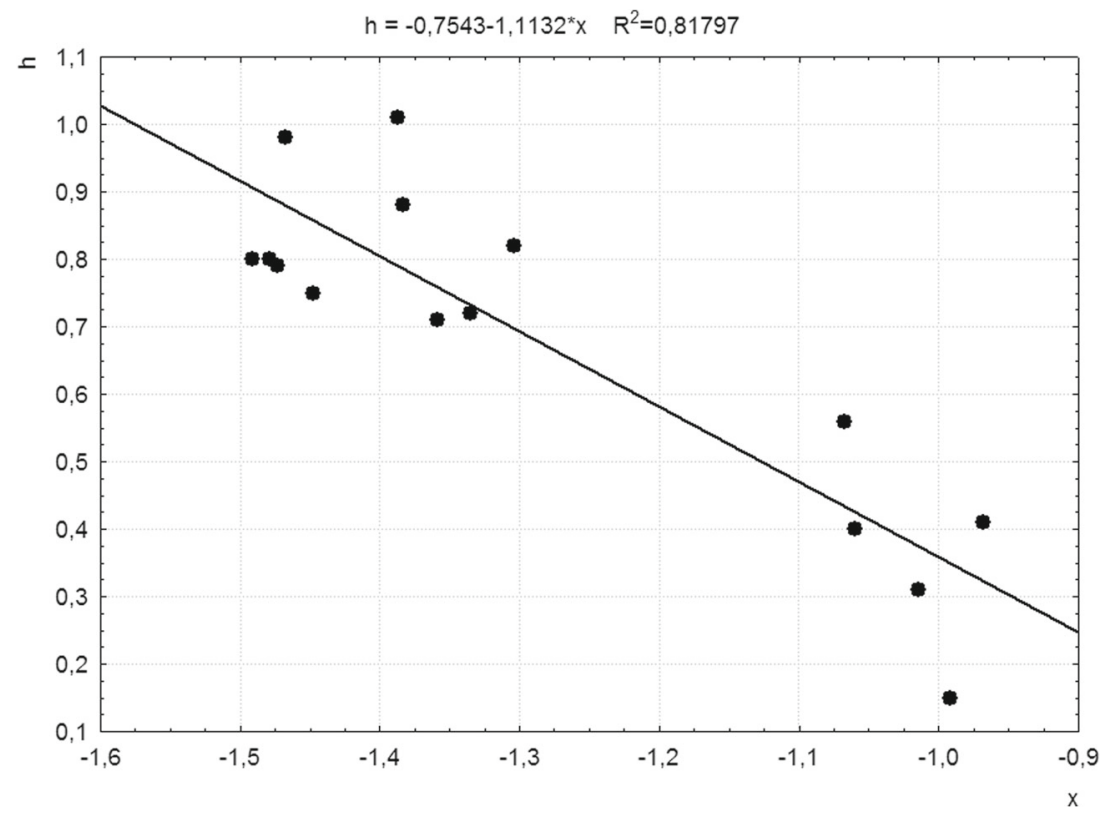

\section{Discussion}

In this paper, the proper method for addressing bathymetric measurements in coastal area waters is demonstrated to be the estimation of the depth using aerial photographs with a coordinate system adjustment for the proper cartographic projection. After calibration using direct measurements, the data obtained enable determination of the actual bathymetry of the area. By using the developed method for estimating the water depth, this type of data can be obtained for large areas and can frequently be updated.

The calculated uncertainty in the depth estimation for the test points indicates an error of $0.2 \mathrm{~m}$. It should be noted that the measurements relate to depths of $1.5 \mathrm{~m}$, which is very shallow. The depth estimation accuracy in such areas determined by lidar is about $0.5 \mathrm{~m}$ (Earlie et al. 2014), which is suitable for coastal areas where calibration measurements are not possible.

Although there are some restrictions on the environmental conditions, calibration can largely eliminate the influence of inhomogeneity in the lighting and optical characteristics of the basin (Carbonneau et al. 2006). Environ-

Table 3 Results of depth estimation and its uncertainty for the test points

\begin{tabular}{llll}
\hline Point & Measured depth $[\mathrm{m}]$ & Estimated depth $[\mathrm{m}]$ & $\Delta h$ \\
\hline s1 & 0.91 & 0.70 & 0.195 \\
s2 & 0.99 & 0.80 & 0.20 \\
s3 & 1.04 & 0.77 & 0.20 \\
s4 & 0.97 & 1.05 & 0.22 \\
s5 & 1.07 & 0.99 & 0.21 \\
\hline
\end{tabular}

mental conditions determine the maximum depth at which the method can be applied. When the brightness of the bottom is insignificant relative to the clarity of the water column, depth estimation is impossible. Suitable examples of such conditions include water with a high concentration of optical pollution and water with a high dimming coefficient. The most favorable conditions are those in which the surface of the sea is smooth, and the water has high transparency. Additional restrictions on the applicability of the method result from the nature of the data used in the depth estimates. The method relates the depth to a pre-defined parameter $\mathrm{N}$. The values cannot be unrestricted because they are limited by the contrast (dynamic range) of the analyzed images. However, this limitation does not play a significant role when the method is applied to shallow coastal waters, which is the model's original purpose.

Numerous studies of the optical classification of marine waters have been performed from optical, hydrological, and bio-optical parameters. These classifications use the absorption-scattering characteristics of water (Jerlov 1976) or the attenuation of the downward irradiance by the chlorophyll a concentration. Currently, the most widely used classification of water divides water bodies into two types: WC1, which is open ocean water, and WC2, which is water in coastal areas and enclosed seas. By using this research to estimate the depths of shallow water areas, it appears reasonable to develop a water classification for such a method. An example might be included in the classification previously reported (Reinart et al. 2003).

Future research should examine the possibility of applying this method to seawater supplied by rivers, which contains a variety of organic and inorganic matter. Considering that modeling of water's additional optical 


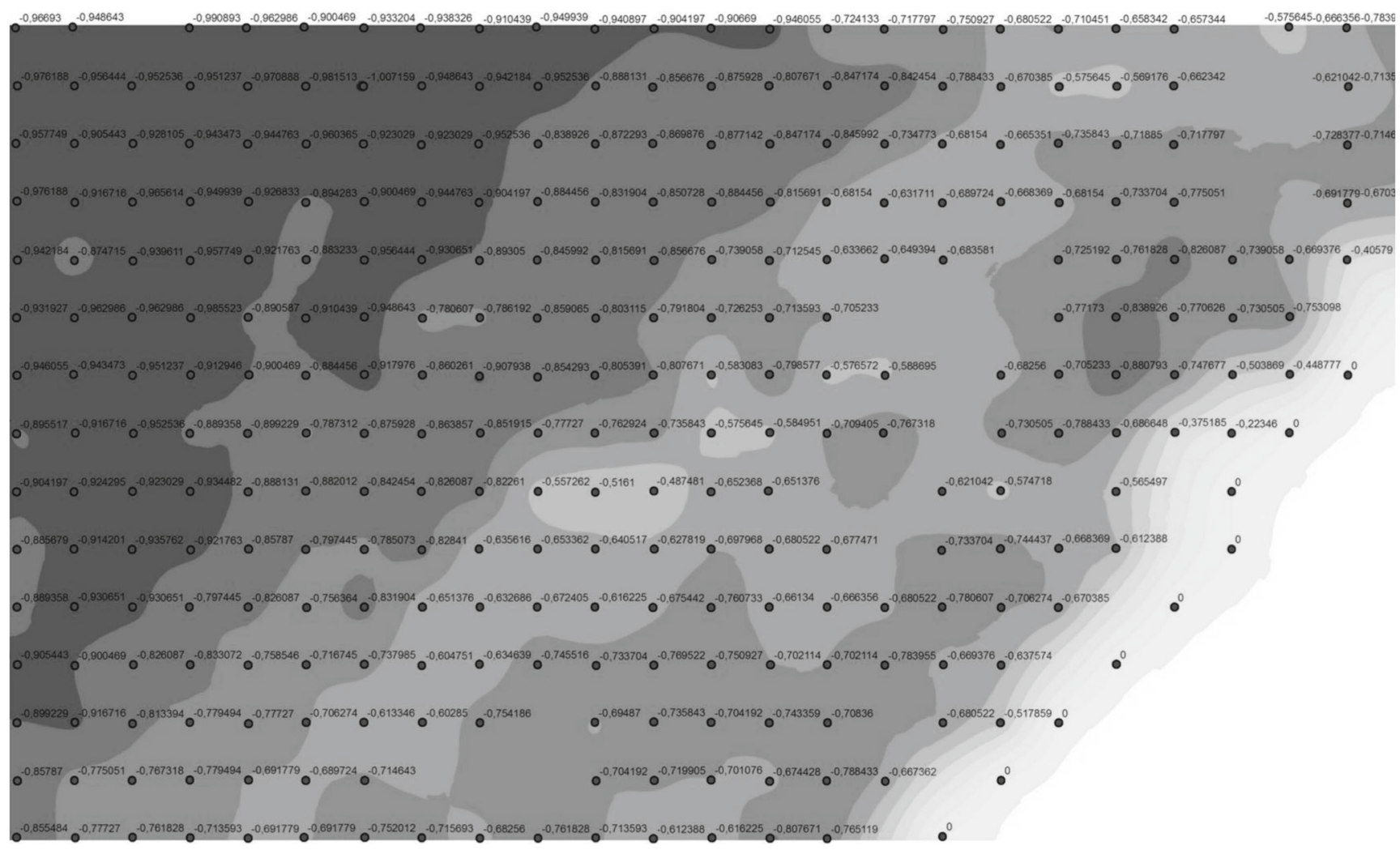

Fig. 5 Bathymetry on a portion of a coastal area

parameters would give better results in optically impure water, it is possible to apply this method to other water areas.

To summarise, the results presented in a broader context may be useful for research into submerged archaeological structures (Doneus et al. 2013) and safety management in coastal zones. In this context, critical areas of application for the proposed method are cases where a quick determination of bathymetric data or its determination in large areas is required. These data are essential for the modeling and determination of rip currents in coastal zones (Scott et al. 2014; Shaw et al. 2014). The method of building an environmental database is also widely applicable for Rapid Environmental Assessment (Eiman et al. 2013; Arnous and Green 2011) and education (Hejmanowska et al. 2015). The proposed method also allows tourism to be improved at the sea coast.

Open Access This article is distributed under the terms of the Creative Commons Attribution 4.0 International License (http:// creativecommons.org/licenses/by/4.0/), which permits unrestricted use, distribution, and reproduction in any medium, provided you give appropriate credit to the original author(s) and the source, provide a link to the Creative Commons license, and indicate if changes were made.

\section{References}

Arnous MO, Green DR (2011) Gis and remote sensing as tools for conducting geo-hazards risk assessment along gulf of aqaba coastal zone egypt. J Coast Conserv 15(4):457-475

Carbonneau PE, Lane SN, Bergeron N (2006) Feature based image processing methods applied to bathymetric measurements from airborne remote sensing in fluvial environments. Earth Surf Process Landf 31(11):1413-1423

Chadyšiene R, Girgždys A (2008) Ultraviolet radiation albedo of natural surfaces. J Environ Eng Landsc Manag 16(2):83-88. https://doi.org/10.3846/1648-6897.2008.16.83-88. http://www. tandfonline.com/doi/abs/10.3846/1648-6897.2008.16.83-88

Dera J, Sagan S (1990) A study of the baltic water optical transparenty. Oceanologia 28, sopot

Doneus M, Doneus N, Briese C, Pregesbauer M, Mandlburger G, Verhoeven G (2013) Airborne laser bathymetry-detecting and recording submerged archaeological sites from the air. J Archaeol Sci 40(4):2136-2151. https://doi.org/10.1016/j.jas.2012.12.021. http://www.sciencedirect.com/science/article/pii/S030544031200 5420

Earlie C, Masselink G, Russell P, Shail R (2014) Application of airborne lidar to investigate rates of recession in rocky coast environments. J Coast Conserv :1-15

Eiman AA, Amr ES, Mohammed S (2013) Environmental assessment of Kuwait bay: an integrated approach. J Coast Conserv 17(3):445-462

Ficek D (2013) Biooptical properties in water lakes of pomerania and their comparison with the properties of the waters of other lakes and the baltic sea. Tech. rep., PAN, sopot 
Gilabert J, Perez-Ruzafa A, Gutierrez JM, Bel-lan A, Moreno V (1995) Light attenuation coefficient in shallow coastal waters from airborne multispectral data: implications for water quality and bottom features estimation. EARSeL Advances Remote Sens $4(1): 76-86$

Hakvoort H, de Haan J, Jordans R, Vos R, Peters S (2000) Towards operational airborne remote sensing of water quality in the netherlands. International Archives of Photogrammetry and Remote Sensing XXXIII(3/2001), part B7. Amsterdam

Hejmanowska B, Kaminski W, Przyborski M, Pyka K, Pyrchla J (2015) Modern remote sensing and the challenges facing education systems in terms of its teaching. In: GomezChova L, LopezMartinez A, CandelTorres I (eds) EDULEARN15: 7th international conference on education and new learning technologies, EDULEARN Proceedings, pp 6549-6558, 7th International Conference on Education and New Learning Technologies (EDULEARN), Barcelona, JUL 06-08, 2015

Janowski A, Przyborski M, Serafin M, Szulwic J (2015) The use of morphological filters and granulometric method to analyze the movement of the molecules in the sea water of the southern baltic sea. Photogrammetry and Remote Sensing

Jerlov N (1976) Marine Optics. Elsevier Oceanography Series, Elsevier Science, http://books.google.pl/books?id=tzwgrtnW_lYC

Kasyk L, Kijewska M, Leyk-Wesolowska M, Kowalewski M, Pyrchla J, Pyrchla K (2016) Research into the movements of surface water masses in the basins adjacent to the port. In: 2016 Baltic Geodetic Congress (BGC Geomatics), pp 191-196. https://doi.org/10.1109/BGC.Geomatics.2016.42

Kumar DA, Kumar JD, Prashanthi DM, Kumar SB, Vinithkumar NV, Kirubagaran R (2014) Post tsunami mangrove evaluation in coastal vicinity of andaman islands, india. J Coast Conserv 18(3):249-255. https://doi.org/10.1007/s11852-014-0312-5

Levin I, Darecki M, Sagan S, Radomyslskaya T (2013) Relationships between inherent optical properties in the baltic sea for application to the underwater imaging problem. Oceanologia 55, gdynia

Łubczonek J, Stateczny A (2003) Concept of neural model of the sea bottom surface. In: Rutkowski L, Kacprzyk J (eds) Neural networks and soft computing, advances in soft computing, vol 19, Physica-Verlag HD, pp 861-866. https://doi.org/10.1007/978-37908-1902-1_135

Lyzenga D (1978) Passive remote sensing techniques for mapping water depth and bottom features. Appl Opt 17

Lyzenga D, Thomson F (1976) Data processing and evaluation for Panama city coastal survey: Bathymetry results. Tech. Rep 121400-1-T. The University of Michigan, Ann Arbor

Maffione RA (2001) Evolution and revolution in measuring ocean optical properties. Oceanography 14(3):9-14

Mobley CD, Sundman LK, Bissett WP, Cahill B (2009) Fast and accurate irradiance calculations for ecosystem models. Biogeosciences Discuss 6:10,625-10,662. www.biogeosciences-discuss. net/6/10625/2009/

Pais-Barbosa J, Veloso-Gomes F, Taveira-Pinto F (2012) Coastal features analysis using gis tools-stretch esmoriz-furadouro.
J Coast Conserv 16(3):269-279. https://doi.org/10.1007/s11852011-0174-z

Polcyn FC, Lyzenga DR (1973) Proceedings symposium on significant results obtained from erts-1. In: Calculation of water Depth from ERTS-MSS Data, SP-327, nASA Publication

Polcyn FC, Brown WL, Sattinger IJ (1970) The measurement of water depth by remote sensing techniques. Tech. Rep 8973-26-F. The University of Michigan, Ann Arbor

Pyrchla J, Kowalewski M, Leyk-Wesolowska M, Pyrchla K (2016) Integration and visualization of the results of hydrodynamic models in the maritime network-centric gis of gulf of gdansk. In: 2016 Baltic Geodetic Congress (BGC Geomatics), pp 159-164. https://doi.org/10.1109/BGC.Geomatics.2016.36

Reinart A, Herlevi A, Arst H, Sipelgas L (2003) Preliminary optical classification of lakes and coastal waters in Estonia and south finland. J Sea Res 49(4):357-366. https://doi.org/10.1016/s13851101(03)00019-4. http://www.sciencedirect.com/science/article/ pii/S1385110103000194, proceedings of the 22nd Conference of the Baltic Oceanographers CBO), Stockholm 2001

Scott T, Masselink G, Austin MJ, Russell P (2014) Controls on macrotidal rip current circulation and hazard. Geomorphology 214:198-215. https://doi.org/10.1016/j.geomorph.2014.02.005. http://www.sciencedirect.com/science/article/pii/ S0169555X14000798

Shaw WS, Goff J, Brander R, Walton T, Roberts A, Sherker S (2014) Surviving the surf zone: towards more integrated rip current geographies. Appl Geogr 54:54-62. https://doi.org/10.1016/j.apgeog. 2014.07.010. http://www.sciencedirect.com/science/article/pii/ S0143622814001660

Stateczny A (2000) The neural method of sea bottom shape modelling for the spatial maritime information system. In: Brebbia CA, Olivella J (eds) Maritime engineering and ports II, Front Portuari Catala; Minist Fomento; Wessex Inst Technol; Univ Politecn Catalunya, Dept Naut Sci \& Engn, Wit Press, Ashurst Lodge, Southampton SO40 7aa, Ashurst, Water Studies Series, vol 9, pp 251-259, 2nd International Conference on Maritime Engineering and Ports, Barcelona, Sep, 2000

Stateczny A, Wlodarczyk-Sielicka M (2014) Self-organizing artificial neural networks into hydrographic big data reduction process. In: Kryszkiewicz M, Cornelis C, Ciucci D, MedinaMoreno J, Motoda H, Ras ZW (eds) Rough sets and intelligent systems paradigms, RSEISP 2014, Infobright Inc, Springer, Berlin, Heidelberger Platz 3, D-14197 Berlin, Germany, Lecture Notes in Computer Science, vol 8537, pp 335-342, 2nd International Conference on Rough Sets and Emerging Intelligent Systems Paradigms (RSEISP) held as part of Joint Rough Set Symposium (JRS), SPAIN, JUL 0913 ,

Tibbetts J, van Proosdij D (2013) Development of a relative coastal vulnerability index in a macro-tidal environment for climate change adaptation. J Coast Conserv 17(4):775-797. https://doi.org/10.1007/s11852-013-0277-9

Wezernak C, Lyzenga D (1975) Analysis of cladophora distribution in lake ontario using remote sensing. Remote Sensing Environ 4 